\title{
Associations between common mental disorders and sexual dissatisfaction in the general population
}

\author{
Ine Vanwesenbeeck, Margreet ten Have and Ron de Graaf
}

\section{Background}

Little is known about the associations between common mental disorders and sexual dissatisfaction in the general population.

\section{Aims}

To assess the associations between the presence of 12month and remitted (lifetime minus 12-month) mood, anxiety and substance use disorders and sexual dissatisfaction in the general population of The Netherlands.

\section{Method}

A total of 6646 participants, aged 18-64, took part in a faceto-face survey using the Composite International Diagnostic Interview 3.0. Childhood trauma, somatic disorders and sexual dissatisfaction were also assessed in an additional questionnaire. Associations were assessed with multivariate regression analyses

\section{Results}

In total, $29 \%$ reported some sexual dissatisfaction. Controlling for demography, somatic disorders and childhood trauma, significant associations with 12-month mood disorder $(B=0.31)$, substance use disorder $(B=0.23)$ and anxiety disorder $(B=0.16)$ were found. Specifically, relatively strong associations were found for alcohol dependence $(B=0.54)$, bipolar disorder $(B=0.45)$ and drug dependence $(B=0.44)$. The association between remitted disorders and sexual dissatisfaction showed significance for the category substance use disorder.

\section{Conclusions}

People with mood, anxiety and substance use disorders show elevated scores on sexual dissatisfaction, even when relevant confounders are controlled for. Sexual satisfaction appears to be reduced most by alcohol and drug dependence and bipolar disorder. Once remitted, substance use disorder shows a persisting association with present sexual dissatisfaction.

\section{Declaration of interest}

None.
Sexuality and mental health are related in many different ways. A vast literature addresses the psychiatric outcomes of sexual experiential variables, notably of child sexual abuse in women ${ }^{1}$ and, to a lesser extent, in men. ${ }^{2}$ Mental ill health has also been associated with non-heterosexuality ${ }^{3}$ and homophobic social reactions. ${ }^{4}$ Another body of literature looks at the sexual outcomes of various psychiatric conditions, the larger part of which addresses sexual dysfunction. ${ }^{5,6}$ Sexual dysfunction is only one aspect of human sexual experience and the focus on it in sexology has been criticised as being notably limited in light of human sexual discontent more generally. ${ }^{7}$ Problematic aspects of sexuality other than dysfunctions, such as dissatisfaction with emotional or relational aspects of sexual experience, are studied to a lesser extent in the context of mental health. Taking the broader view of sexual (dis)satisfaction in relation to mental health is desirable. Although the body of evidence on the determinants of sexual (dis)satisfaction is sometimes contradictory, sexual dissatisfaction has rather consistently been associated with being female, particularly when older, ${ }^{8}$ having been sexually victimised ${ }^{9}$ and having low (somatic) health status. ${ }^{10}$ When studying the relationship between sexual dissatisfaction and mental health, such variables need to be taken into account.

The psychiatric conditions mostly studied as sexual correlates are the common mental disorders such as depression, ${ }^{11,12}$ anxiety disorders $^{5}$ and substance use disorders. ${ }^{13}$ Most research has studied patient samples. Overall, a negative relationship between psychiatric conditions and sexual function or satisfaction is found, ${ }^{14}$ although a minority of patients report an increase in sexual interest and function. ${ }^{11}$ Bipolar disorder is associated with a reduction in sexual desire in depressive phases, but with hypersexual and promiscuous behaviour in individuals in manic phases. ${ }^{6,15}$ There is some evidence that, in comparison with other psychiatric conditions, associations of sexual problems with heroin addiction are notably strong. ${ }^{16}$ However, most studies involved only one specific disorder. Thus, comparison of specific psychiatric conditions and their relationship with sexual (dys)function or general sexual (dis)satisfaction, is relatively rare. So are studies among the general population in this area. Questions remain about the extent to which divergent mental health problems are associated with sexual dissatisfaction in the general population. In addition, population studies on psychiatric epidemiology have provided evidence that after remittance, notably of depression, residual debilitating effects in social, emotional and physical domains of life can still exist $;{ }^{17,18}$ however, to our knowledge no study has addressed residual effects of a variety of mental disorders on sexual dissatisfaction. In this paper, data from the first wave of The Netherlands Mental Health Survey and Incidence Study-2 (NEMESIS-2) were used to study, among the general population, the associations between three categories of common mental disorders (mood, anxiety and substance use disorders) and general sexual dissatisfaction. To what extent is mental health associated with present general sexual dissatisfaction? How does this differ between categories of disorders and specific disorders? In addition, we investigated whether sexual dissatisfaction continues after the various mental disorders have remitted by studying the associations between lifetime minus 12-month disorders and present sexual dissatisfaction. 


\section{Method}

\section{Design and sample}

In NEMESIS-2, a multistage, stratified random sampling procedure was applied. A random sample of 184 of the 443 existing municipalities was drawn. In these municipalities, a random sample of addresses of private households from postal registers was drawn. Based on the most recent birthday at first contact within the household, an individual aged 18-64 with sufficient fluency in the Dutch language was randomly selected for interview. The study was approved by a medical ethics committee and respondents provided written informed consent. Selected households received a letter from the Dutch Minister of Health, Welfare and Sport, in which the study was explained and recommended. Households were contacted by telephone, or visited in person if no telephone number was available, at least ten times during November 2007 to July 2009. The response rate was $65.1 \%$. The sample was nationally representative, although younger participants were somewhat underrepresented. In total 6646 people participated. For a more detailed description of the design and fieldwork see de Graaf et al. ${ }^{19}$

\section{Measurement}

Mental disorders. We assessed DSM-IV disorders ${ }^{20}$ using the Composite International Diagnostic Interview (CIDI) 3.0, ${ }^{21}$ which was developed in the World Mental Health Surveys. ${ }^{22-24}$ Both 12-month and lifetime prevalence were measured for the following disorders: mood (major depression, dysthymia, bipolar disorder), anxiety (panic disorder, agoraphobia (without panic disorder), social phobia, specific phobia, generalised anxiety disorder) and substance use disorders (alcohol/drug absuse and dependence; the drugs investigated ranged from sedatives and tranquillisers to hypnotics and opiates). Clinical calibration studies conducted in various countries have found that CIDI $3.0^{21}$ and earlier versions ${ }^{25,26}$ assess anxiety, mood and substance use disorders with generally good validity compared with masked clinical reappraisal interviews.

Sexual dissatisfaction. Sexual dissatisfaction was assessed with the question 'How satisfied with your sexual life are you at present?' Scores on this item showed high item-rest correlations in data from a multiple-item scale on sexual satisfaction in a large Dutch survey. ${ }^{27}$ Answers were on a four-point scale ranging from very much satisfied (score 1) to not satisfied (score 4 ).

Somatic disorders. Presence of one or more conditions from a standard checklist of 17 chronic physical disorders treated or monitored by a medical doctor in the past 12 months was assessed. These conditions were: respiratory disorders (asthma, chronic obstructive pulmonary disease, chronic bronchitis, emphysema), cardiovascular disorders (severe heart disease, heart attack, hypertension, stroke), digestive disorders (stomach or intestinal ulcers, severe intestinal disorders such as irritable bowel syndrome), diabetes, thyroid disorder, chronic back pain, arthritis, migraine, impaired vision or hearing and other chronic physical disorders. Comparisons between self-reports of chronic physical disorders and medical records show moderate to good concordance. $^{28}$

Sociodemographics. These included gender, age, educational level, living with a partner or not, being sexually active or not, having children, degree of urbanisation and being employed or not.
Childhood trauma. Participants were asked whether, before the age of 16, they had experienced emotional neglect, psychological abuse or physical abuse on two or more occasions, or sexual abuse on one or more occasion.

\section{Statistical analyses}

Of the 6646 respondents, 140 received a shortened version of the questionnaire and were not asked about sexual dissatisfaction, somatic disorder and childhood trauma. Furthermore, 116 respondents answered 'don't know' and 172 persons refused to answer the question on sexual dissatisfaction. These respondents were omitted from the analyses, which means that the final number of respondents in the analyses was 6218 .

The data were weighted to correct for differences in the response rates among several population groups and for differences in the probability of selection of respondents within households, ${ }^{19}$ so that it was possible to generalise the results to the national population. Robust standard errors were calculated by using the first-order Taylor-series linearisation method, as implemented in Stata 11 on Windows, in order to obtain corrected 95\% confidence intervals and $P$-values. ${ }^{29}$ Summary statistics were used to describe correlates of sexual dissatisfaction. Multivariate regression analyses were performed to examine the association between mental disorders and sexual dissatisfaction, adjusted for gender, age, partner status and being sexually active (Model 1) and additionally for having children, paid job, education, urbanicity of residence, somatic disorder and childhood trauma (Model 2). As the outcome variable sexual dissatisfaction was measured on a narrow four-point scale and the distribution of these data was somewhat skewed, we also performed the analyses with multinomial logistic regression analyses. These analyses yielded similar results and are available from the authors on request.

\section{Results}

\section{Correlates of sexual dissatisfaction}

A minority of the study sample reported dissatisfaction with their sexual lives at present. Overall, $8.1 \%$ of the sample reported being 'not satisfied'; another $20.6 \%$ reported being 'a little satisfied'. Table 1 shows the relative sexual dissatisfaction among the Dutch population as distinguished by a number of demographic variables and Table 2 by variables related to somatic health, childhood trauma and whether sexually active. Many of these variables show significant associations with sexual dissatisfaction: participants of older age, not living with a partner, without children (at home), without a paid job, with a lower education, living in urban areas, who reported somatic disorders, who experienced childhood abuse and neglect and who were not sexually active all showed more sexual dissatisfaction. No differences were found between men and women.

\section{Associations between 12-month mental disorders and sexual dissatisfaction}

Table 3 details categories of 12-month common mental disorders as correlates of sexual dissatisfaction (see online Table DS1 for the results by specific disorder). At the bivariate level, all categories of disorders investigated, with the exception of agoraphobia and alcohol abuse (Table DS1), are significantly correlated with sexual dissatisfaction.

The results of the multivariate analyses, controlling for gender, age, partner status and being sexually active (Table 4, Model 1) and, additionally, for all relevant demographic variables, somatic 


\begin{tabular}{|c|c|c|c|c|c|c|c|}
\hline & \multirow[b]{2}{*}{$n$} & \multicolumn{5}{|c|}{ Sexual satisfaction } & \multirow[b]{2}{*}{$P$} \\
\hline & & $\begin{array}{l}\text { Dissatisfaction } \\
\text { Mean }\end{array}$ & $\begin{array}{l}\text { Very much } \\
\text { satisfied, \% } \\
(n=1237)\end{array}$ & $\begin{array}{c}\text { Very } \\
\text { satisfied, \% } \\
(n=3056)\end{array}$ & $\begin{array}{c}\text { A little } \\
\text { satisfied, \% } \\
(n=1341)\end{array}$ & $\begin{array}{c}\text { Not } \\
\text { satisfied, \% } \\
(n=584)\end{array}$ & \\
\hline \multicolumn{8}{|l|}{ Gender } \\
\hline Male & 2817 & 2.17 & 20.8 & 49.9 & 21.3 & 8.1 & \\
\hline Female & 3401 & 2.15 & 20.9 & 51.0 & 20.0 & 8.1 & 0.7433 \\
\hline \multicolumn{8}{|l|}{ Age, years } \\
\hline $18-24$ & 430 & 2.00 & 28.6 & 50.7 & 13.2 & 7.5 & \\
\hline $25-34$ & 1068 & 2.11 & 26.7 & 43.2 & 22.6 & 7.5 & \\
\hline $35-44$ & 1622 & 2.13 & 21.2 & 52.2 & 19.3 & 7.4 & \\
\hline $45-54$ & 1498 & 2.20 & 17.1 & 54.3 & 20.0 & 8.7 & \\
\hline 55-64 & 1600 & 2.30 & 14.4 & 50.9 & 25.6 & 9.2 & $<0.0001$ \\
\hline \multicolumn{8}{|l|}{ Partner status } \\
\hline Living with partner & 4326 & 2.03 & 22.1 & 56.6 & 17.6 & 3.7 & \\
\hline Not living with partner & 1892 & 2.46 & 17.9 & 36.5 & 27.4 & 18.1 & $<0.0001$ \\
\hline \multicolumn{8}{|l|}{ Having children } \\
\hline With children living at home & 2732 & 2.08 & 21.2 & 55.4 & 17.9 & 5.5 & \\
\hline With children not at home & 1596 & 2.27 & 16.2 & 50.5 & 22.9 & 10.4 & \\
\hline Without children & 1890 & 2.20 & 22.9 & 44.1 & 22.9 & 10.2 & $<0.0001$ \\
\hline \multicolumn{8}{|l|}{ Employment situation } \\
\hline With paid job & 4700 & 2.12 & 21.5 & 51.8 & 19.8 & 7.0 & \\
\hline Without paid job & 1518 & 2.29 & 18.6 & 45.9 & 23.5 & 12.0 & $<0.0001$ \\
\hline \multicolumn{8}{|l|}{ Education } \\
\hline Primary, basic vocational & 278 & 2.28 & 12.9 & 55.9 & 21.6 & 9.6 & \\
\hline Lower secondary & 1680 & 2.14 & 22.7 & 50.2 & 17.9 & 9.2 & \\
\hline Higher secondary & 2010 & 2.14 & 21.3 & 50.8 & 20.1 & 7.8 & \\
\hline Higher professional, university & 2250 & 2.17 & 20.5 & 48.9 & 23.3 & 7.4 & 0.0115 \\
\hline \multicolumn{8}{|l|}{ Urbanicity of residence } \\
\hline very low & 838 & 2.08 & 23.0 & 52.2 & 18.1 & 6.6 & \\
\hline Low & 1348 & 2.11 & 20.6 & 54.2 & 18.5 & 6.7 & \\
\hline Medium & 1407 & 2.21 & 18.5 & 51.2 & 21.3 & 8.9 & \\
\hline High & 1639 & 2.14 & 23.7 & 46.8 & 21.3 & 8.2 & \\
\hline very high & 986 & 2.25 & 17.4 & 50.1 & 23.0 & 9.6 & 0.0032 \\
\hline
\end{tabular}

\begin{tabular}{|c|c|c|c|c|c|c|c|}
\hline & \multirow[b]{2}{*}{$n$} & \multicolumn{6}{|c|}{ Sexual satisfaction } \\
\hline & & $\begin{array}{l}\text { Dissatisfaction } \\
\text { Mean }\end{array}$ & $\begin{array}{l}\text { Very much } \\
\text { satisfied, \% } \\
(n=1237)\end{array}$ & $\begin{array}{c}\text { Very } \\
\text { satisfied, \% } \\
(n=3056)\end{array}$ & $\begin{array}{c}\text { A little } \\
\text { satisfied, \% } \\
(n=1341)\end{array}$ & $\begin{array}{c}\text { Not } \\
\text { satisfied, \% } \\
(n=584)\end{array}$ & $P$ \\
\hline \multicolumn{8}{|c|}{ Somatic disorder } \\
\hline No & 3978 & 2.11 & 22.0 & 51.9 & 19.2 & 6.9 & \\
\hline Yes & 2240 & 2.26 & 18.4 & 47.6 & 23.5 & 10.5 & $<0.0001$ \\
\hline \multicolumn{8}{|c|}{ Emotional neglect } \\
\hline No & 5239 & 2.13 & 21.3 & 51.9 & 19.6 & 7.2 & \\
\hline Yes & 979 & 2.35 & 17.8 & 42.2 & 26.9 & 13.1 & $<0.0001$ \\
\hline \multicolumn{8}{|c|}{ Psychological abuse } \\
\hline No & 5128 & 2.13 & 21.4 & 51.7 & 19.6 & 7.2 & \\
\hline Yes & 1090 & 2.33 & 17.7 & 44.3 & 25.7 & 12.3 & $<0.0001$ \\
\hline \multicolumn{8}{|c|}{ Physical abuse } \\
\hline No & 5697 & 2.14 & 21.1 & 51.4 & 19.9 & 7.6 & \\
\hline Yes & 521 & 2.39 & 17.3 & 39.7 & 29.3 & 13.6 & $<0.0001$ \\
\hline \multicolumn{8}{|c|}{ Sexual abuse } \\
\hline No & 5712 & 2.14 & 21.1 & 51.2 & 19.9 & 7.8 & \\
\hline Yes & 506 & 2.36 & 16.9 & 42.1 & 29.0 & 11.9 & $<0.0001$ \\
\hline \multicolumn{8}{|c|}{ Sexually active } \\
\hline No & 896 & 2.84 & 9.0 & 27.1 & 34.8 & 29.1 & \\
\hline Yes & 5298 & 2.06 & 22.5 & 53.8 & 18.6 & 5.1 & $<0.0001$ \\
\hline
\end{tabular}




\begin{tabular}{|c|c|c|c|c|c|c|c|}
\hline & \multirow[b]{2}{*}{$n$} & \multicolumn{6}{|c|}{ Sexual satisfaction } \\
\hline & & $\begin{array}{l}\text { Dissatisfaction } \\
\text { Mean }\end{array}$ & $\begin{array}{l}\text { Very much } \\
\text { satisfied, \% } \\
(n=1237)\end{array}$ & $\begin{array}{c}\text { Very } \\
\text { satisfied, \% } \\
(n=3056)\end{array}$ & $\begin{array}{c}\text { A little } \\
\text { satisfied, \% } \\
(n=1341)\end{array}$ & $\begin{array}{c}\text { Not } \\
\text { satisfied, \% } \\
(n=584)\end{array}$ & $P$ \\
\hline \multicolumn{8}{|c|}{ Any mood disorder } \\
\hline No & 5832 & 2.13 & 21.1 & 51.7 & 20.3 & 6.9 & \\
\hline Yes & 386 & 2.60 & 17.0 & 31.6 & 26.1 & 25.3 & $<0.0001$ \\
\hline \multicolumn{8}{|c|}{ Any anxiety disorder } \\
\hline No & 5586 & 2.13 & 21.0 & 51.8 & 19.9 & 7.2 & \\
\hline Yes & 632 & 2.39 & 18.8 & 38.6 & 27.0 & 15.6 & $<0.0001$ \\
\hline \multicolumn{8}{|c|}{ Any substance use disorder } \\
\hline No & 5936 & 2.14 & 21.3 & 50.8 & 20.1 & 7.8 & \\
\hline Yes & 282 & 2.42 & 13.2 & 44.4 & 29.5 & 12.9 & 0.0002 \\
\hline \multicolumn{8}{|c|}{ Any Axis I disorder } \\
\hline No & 5169 & 2.11 & 21.6 & 52.4 & 19.5 & 6.5 & \\
\hline Yes & 1049 & 2.40 & 17.0 & 41.5 & 26.0 & 15.5 & $<0.0001$ \\
\hline
\end{tabular}

disorders and childhood trauma (Model 2) show that 'any Axis I disorder' and all three categories of mental disorders are significantly associated with sexual dissatisfaction in both models. In Model 2, sexual dissatisfaction scores of people with 'any mood disorder' are, on average, 0.31 higher than those without any mood disorder. For 'any substance use disorder' and 'any anxiety disorder' these figures are 0.23 and 0.16 respectively. When looking at the separate disorders, associations with sexual dissatisfaction in Model 1 are significant for (in order of coefficient size) alcohol dependence, bipolar disorder, drug dependence, drug abuse, social phobia, major depression, panic disorder, generalised anxiety disorder and specific phobia. When also controlling for relevant demographic confounders, somatic disorders and childhood trauma (Model 2), only the associations with panic disorder and generalised anxiety disorder were no longer significant. In both models, the results of the multivariate analyses were not significant for dysthymia, agoraphobia and alcohol abuse.

\section{Associations between remitted mental disorders and sexual dissatisfaction}

Associations between lifetime minus 12-month mental disorders and sexual satisfaction in the multivariate analyses (Table 5, Model 1) are significant for 'any Axis I disorder' and for the categories any substance use disorder and any anxiety disorder. Specifically, agoraphobia and social phobia show significant associations with present sexual dissatisfaction. Mood disorder was not significantly associated with sexual dissatisfaction, categorically nor specifically. When other relevant demographic variables, somatic disorders and childhood trauma are additionally entered into the model (Table 5, Model 2), the association with any anxiety disorder

\begin{tabular}{|c|c|c|c|c|c|}
\hline \multirow[b]{3}{*}{ 12-month disorders } & \multirow[b]{3}{*}{$n$} & \multicolumn{4}{|c|}{ Sexual dissatisfaction } \\
\hline & & \multicolumn{2}{|l|}{ Model $1^{a}$} & \multicolumn{2}{|l|}{ Model $2^{\mathrm{b}}$} \\
\hline & & Adjusted coefficient $(95 \% \mathrm{Cl})$ & $P$ & Adjusted coefficient (95\% Cl) & $P$ \\
\hline Any mood disorder & 386 & $0.35(0.23$ to 0.47$)$ & $<0.001$ & $0.31(0.18$ to 0.43$)$ & $<0.001$ \\
\hline Major depression & 341 & $0.30(0.15$ to 0.45$)$ & $<0.001$ & $0.25(0.10$ to 0.40$)$ & 0.001 \\
\hline Dysthymia & 59 & $0.40(-0.07$ to 0.86$)$ & 0.094 & $0.31(-0.14$ to 0.76$)$ & 0.173 \\
\hline Bipolar disorder & 41 & $0.52(0.16$ to 0.87$)$ & 0.004 & $0.45(0.12$ to 0.78$)$ & 0.008 \\
\hline Any anxiety disorder & 632 & $0.21(0.12$ to 0.30$)$ & $<0.001$ & $0.16(0.07$ to 0.25$)$ & 0.001 \\
\hline Panic disorder & 75 & $0.30(0.06$ to 0.54$)$ & 0.013 & $0.22(-0.02$ to 0.45$)$ & 0.072 \\
\hline Agoraphobia & 23 & $-0.02(-0.44$ to 0.41$)$ & 0.942 & $-0.14(-0.55$ to 0.26$)$ & 0.481 \\
\hline Social phobia & 221 & $0.33(0.18$ to 0.48$)$ & $<0.001$ & 0.27 (0.12 to 0.42$)$ & $<0.001$ \\
\hline Specific phobia & 326 & $0.21(0.07$ to 0.34$)$ & 0.003 & $0.15(0.02$ to 0.29$)$ & 0.026 \\
\hline Generalised anxiety disorder & 107 & $0.22(0.01$ to 0.43$)$ & 0.044 & $0.17(-0.03$ to 0.38$)$ & 0.101 \\
\hline Any substance use disorder & 282 & $0.26(0.15$ to 0.36$)$ & $<0.001$ & $0.23(0.12$ to 0.34$)$ & $<0.001$ \\
\hline Alcohol abuse & 183 & $0.14(-0.01$ to 0.30$)$ & 0.074 & $0.13(-0.03$ to 0.29$)$ & 0.114 \\
\hline Alcohol dependence & 33 & $0.56(0.31$ to 0.81$)$ & $<0.001$ & $0.54(0.30$ to 0.78$)$ & $<0.001$ \\
\hline Drug abuse & 44 & $0.36(0.14$ to 0.58$)$ & 0.002 & $0.29(0.06$ to 0.51$)$ & 0.012 \\
\hline Drug dependence & 37 & $0.48(0.09$ to 0.87$)$ & 0.016 & $0.44(0.06$ to 0.82$)$ & 0.023 \\
\hline Any Axis I disorder & 1049 & $0.24(0.18$ to 0.30$)$ & $<0.001$ & $0.20(0.14$ to 0.27$)$ & $<0.001$ \\
\hline \multicolumn{6}{|c|}{$\begin{array}{l}\text { Results in bold are significant. } \\
\text { a. Model 1: adjusted regression coefficient for gender, age, partner status, being sexually active. } \\
\text { b. Model 2: adjusted regression coefficient for gender, age, partner status, being sexually active, having children, paid job, education, urbanicity of residence, somatic disease, four } \\
\text { types of childhood trauma (emotional neglect, psychological abuse, physical abuse, sexual abuse). }\end{array}$} \\
\hline
\end{tabular}




\begin{tabular}{|c|c|c|c|c|c|}
\hline \multirow[b]{3}{*}{ Lifetime minus 12 -month disorders } & \multirow[b]{3}{*}{$n$} & \multicolumn{4}{|c|}{ Sexual dissatisfaction } \\
\hline & & \multicolumn{2}{|l|}{ Model $1^{\mathrm{a}}$} & \multicolumn{2}{|l|}{ Model $2^{b}$} \\
\hline & & Adjusted coefficient $(95 \% \mathrm{Cl})$ & $P$ & Adjusted coefficient $(95 \% \mathrm{Cl})$ & $P$ \\
\hline Any mood disorder & 932 & $0.05(-0.02$ to 0.13$)$ & 0.176 & $0.01(-0.07$ to 0.09$)$ & 0.752 \\
\hline Major depression & 891 & $0.06(-0.02$ to 0.14$)$ & 0.132 & $0.02(-0.06$ to 0.11$)$ & 0.581 \\
\hline Dysthymia & 28 & $0.19(-0.12$ to 0.51$)$ & 0.230 & $0.09(-0.24$ to 0.41$)$ & 0.603 \\
\hline Bipolar disorder & 36 & $-0.16(-0.44$ to 0.13$)$ & 0.276 & $-0.22(-0.52$ to 0.07$)$ & 0.137 \\
\hline Any anxiety disorder & 625 & $0.10(0.01$ to 0.19$)$ & 0.023 & $0.06(-0.03$ to 0.15$)$ & 0.159 \\
\hline Panic disorder & 171 & $-0.03(-0.19$ to 0.14$)$ & 0.761 & $-0.07(-0.23$ to 0.10$)$ & 0.431 \\
\hline Agoraphobia & 41 & $0.41(0.11$ to 0.72$)$ & 0.008 & $0.35(0.06$ to 0.65$)$ & 0.019 \\
\hline Social phobia & 359 & $0.15(0.01$ to 0.29$)$ & 0.038 & $0.11(-0.03$ to 0.24$)$ & 0.115 \\
\hline Specific phobia & 193 & $0.10(-0.02$ to 0.22$)$ & 0.110 & $0.06(-0.07$ to 0.18$)$ & 0.350 \\
\hline Generalised anxiety disorder & 180 & $0.10(-0.05$ to 0.24$)$ & 0.197 & $0.02(-0.12$ to 0.17$)$ & 0.747 \\
\hline Any substance use disorder & 794 & $0.12(0.03$ to 0.20$)$ & 0.006 & 0.09 (0.01 to 0.17$)$ & 0.032 \\
\hline Alcohol abuse & 607 & $0.07(-0.02$ to 0.16$)$ & 0.143 & $0.06(-0.04$ to 0.15$)$ & 0.256 \\
\hline Alcohol dependence & 74 & $0.10(-0.09$ to 0.29$)$ & 0.298 & $0.02(-0.16$ to 0.21$)$ & 0.795 \\
\hline Drug abuse & 169 & $0.12(-0.03$ to 0.27$)$ & 0.118 & $0.06(-0.08$ to 0.21$)$ & 0.395 \\
\hline Drug dependence & 63 & $0.17(-0.13$ to 0.47$)$ & 0.273 & $0.12(-0.16$ to 0.41$)$ & 0.393 \\
\hline Any Axis I disorder & 1518 & $0.09(0.03$ to 0.16$)$ & 0.005 & $0.07(0.01$ to 0.14$)$ & 0.023 \\
\hline
\end{tabular}

was no longer significant. Associations between present sexual dissatisfaction and 'any Axis I disorder', 'any substance use disorder' and agoraphobia, even when remitted for 12 months or longer, still remained significant.

\section{Discussion}

\section{Strengths and limitations}

To our knowledge, this is one of the first studies in a representative sample of the adult population in which the relationship between a broad range of mental disorders and sexual dissatisfaction has been investigated. Several strengths of the study are noteworthy. First, because of the size and representativeness of the sample, its external validity is high. The same is true for its internal validity, because of the use of a structured diagnostic interview to measure mental disorders. Moreover, the extensiveness of the additional questionnaire allowed controlling for relevant confounders. Considering the relevance of childhood trauma as a confounder, it should be mentioned as a minor shortcoming of our diagnostic interview that it did not measure post-traumatic stress disorder.

Another minor limitation relates to the prevalence estimates in NEMESIS-2. The study excluded people who were unable to understand the Dutch language well and people that were homeless or who remained institutionalised for long periods. However, as such people make up only a very small proportion of the Dutch population, overall prevalence rates are not affected to a large extent. Another limitation is the cross-sectional design of the study. Although NEMESIS-2 has a longitudinal design, we made use of data from the first wave only, because sexual dissatisfaction was only measured in the first wave. It remains undetermined whether mental problems cause sexual dissatisfaction, or vice versa, or both. Considering the possible negative and debilitating effects of mental disorders, it seems plausible to at least suppose an effect from them on sexual satisfaction. Our findings here do, moreover, support such a causality by providing evidence that the negative effects of mood and anxiety disorders on sexual satisfaction seem not to last after the psychiatric problems remitted. Nevertheless, it is possible that sexual dissatisfaction (also) facilitates the aetiology of psychiatric disorders, or impedes recovery from them. As is often the case, a two-way process with both forms of ill health sustaining each other might be possible.

Another drawback is the non-specificity of the sexual dissatisfaction measure used in this study. Basically, we do not know what sexual (dis)satisfaction actually pertains to here. Does it relate to sexual meanings or emotions, sexual experiences, relational satisfaction, sexual communication, the frequency of sexual behaviour, sexual function, or a combination of those? On the other hand, using 'sexual dissatisfaction' as a broader and thus more complete indicator of sexual health than 'sexual dysfunctions', is an advantage of the study and a welcome addition to the majority of dysfunction-focused studies in this field. But to what extent and how exactly the two concepts differ is unclear, although some recent evidence indicates that, in lay people's definitions, sexual satisfaction derives from positive sexual experiences (such as mutual pleasure) rather than from the absence of sexual dysfunction. ${ }^{30}$

In addition, medication taken for a psychiatric condition may further hamper sexual experience. Medication may directly affect sexual function (notably by affecting neurotransmission) or work indirectly through negative effects on physiology (such as perspiration, smell or energy level) or appearance (such as weight or skin). ${ }^{31}$ Our study does not overcome one of the general problems found in research in this area, which is that it is often unclear whether effects are to be attributed to the condition itself or to medication. However, since we know that only a small minority of respondents in this study had medication prescribed during their 12-month disorder (varying between $1 \%$ and 3.5\% for the different types of disorders), a large effect thereof is not to be expected.

\section{Correlates of sexual dissatisfaction}

First, this study has shown, as anticipated, that many demographic variables, somatic disorders and childhood trauma are indeed related to sexual dissatisfaction in expected ways. However, it 
was contrary to expectations ${ }^{8}$ that we found that sexual dissatisfaction was not greater in women than men. A recent sexual-health-focused survey among the Dutch population (aged 15-71 years of age $)^{32}$ did find a small but significant gender difference in sexual satisfaction, with $61.0 \%$ of women and $63.4 \%$ of men reporting they were satisfied with their sexual lives (scores 4 and 5 on a five-point scale). Responding to a fiveinstead of a four-point scale may be one reason for these slightly different findings. Another reason that no gender differences were found may have been that participants thought of different aspects of sexual satisfaction in answering the question.

Second, the study has shown that general sexual dissatisfaction is moderately but consistently associated with a range of mood, substance use and anxiety disorders. This is even the case when all demographic and experiential variables (somatic disorders, childhood trauma) are controlled for.

Third, sexual dissatisfaction was found to be associated with the category any substance use disorder even when the latter had already remitted for 12 months or more. This was the case for any anxiety disorder (and specifically for social phobia) only before controlling for the experiential variables, but in neither case for any mood disorder. That agoraphobia specifically was associated with present sexual dissatisfaction after remission, whereas no associations were found before remission, is a remarkable finding in this study. It is difficult to explain this finding. However, because of the low prevalence and thus small number of individuals with agoraphobia, the positive association might well be the result of chance and thus a false positive.

Overall, the associations of sexual dissatisfaction with mood and anxiety disorders may have been attenuated by the oppositely directed effects they may have on sexual dissatisfaction. Although the evidence for negative effects of mood and anxiety disorders on sexuality is strong, some patients, on the other hand, seem to experience positive effects. ${ }^{11,14}$ In a study by Bancroft et al, $44 \%$ of men with depression reported reduced sexual interest, but $12 \%$ reported an increase. ${ }^{11}$ In our study, negative and positive effects may have, to a certain extent, cancelled each other out in the analyses.

\section{Various associations compared}

When looking at the various associations found, alcohol and drug dependence (but not so alcohol abuse, and drug abuse to a lesser extent) show a somewhat more solid relationship with sexual dissatisfaction in comparison with mood and, particularly, anxiety disorders. The fact that alcohol abuse (as opposed to dependence) was not associated with sexual dissatisfaction may be seen as an illustration of the normative character of alcohol use in The Netherlands, a habit not necessarily reflecting mental problems and, apparently, not bearing a relationship to sexual problems, either causally or covariantly. The suggestion that alcohol abuse might not necessarily indicate psychopathology has been discussed previously. ${ }^{33}$ Alcohol dependence however, may be reflective of pathology and as such related to, among others, sexual dissatisfaction. The differential effects of occasional $v$. prolonged alcohol use on sexual experience have been well documented. ${ }^{34}$ Occasional and moderate use may have notable positive effects, whereas heavy and long-lasting use, notably when out of control, such as in dependence, may strongly obstruct sexual performance and experience.

The suggestion that drug dependence is strongly associated with sexual dissatisfaction is also supported by other studies. For instance a Turkish study showed that psychiatric patients who were addicted to heroin significantly more often had sexual problems than out-patients in remission with schizophrenia, patients with bipolar affective disorders and a healthy control group. ${ }^{16}$ The sexual disturbance and possibly connected dissatisfaction caused by opiate-induced hypogonadism is well documented in the literature, with hormone substitution in individuals addicted to heroin strongly advised by some authors. ${ }^{35}$ Others, however, have attributed sexual problems not to the opiate but more to the underlying psychiatric problems. ${ }^{36}$

We also found the association between sexual dissatisfaction and bipolar disorder to be relatively strong, at least when individuals were still experiencing the disorder. This is consistent with the fact that bipolar disorder is one of the most severe common mental disorders, together with alcohol and drug dependence. $^{37}$ The more severe mental disorders most probably have a relatively strong negative effect on daily life and functioning, with likewise negative effects on sexual satisfaction.

\section{Implications}

Our findings strongly endorse the existence of a significant relationships between mental health and overall sexual satisfaction. Therefore, the results of this study highlight the need for appropriate attention to be given to sexuality in mental health clinical practice, residential or otherwise. Not least the issue of sexual dissatisfaction in patients with drug addiction (as opposed to 'mere' drug abuse) could be addressed in treatment plans. Explicitly exploring sexuality with patients with dependence may even provide an extra motivation to recover from their dependency. Finally, this study draws attention to the need for more research into the associations between mental health and a variety of indicators of sexual health and satisfaction, indicators that are broader than the dysfunctions mostly studied but more specific than the broad measure of overall satisfaction used here.

Ine Vanwesenbeeck, PhD, Department of Interdisciplinary Social Science, Utrech University, Utrecht and Rutgers WPF, Utrecht; Margreet ten Have, PhD, Ron de Graaf, PhD, Netherlands Institute of Mental Health and Addiction, Utrecht, The Netherlands

Correspondence: Ine Vanwesenbeeck, Department of Interdisciplinary Socia Science, Utrecht University, PO Box 80140, 3508 TC Utrecht, The Netherlands. Email: W.M.A.vanwesenbeeck@uu.nl

First received 12 Jul 2013, final revision 16 Dec 2013, accepted 17 Feb 2014

\section{References}

1 Bebbington $\mathrm{P}$, Jonas $\mathrm{S}$, Kuipers $\mathrm{E}$, King $\mathrm{M}$, Cooper $\mathrm{C}$, Brugha $\mathrm{T}$, et al. Childhood sexual abuse and psychosis: data from a cross-sectional national psychiatric survey in England. Br J Psychiatry 2011; 199: 29-37.

2 King M, Coxell A, Mezey G. Sexual molestation of males: associations with psychological disturbance. Br J Psychiatry 2002; 181: 153-7.

3 Sandfort TGM, de Graaf R, Bijl RV, Schnabel P. Same-sex sexual behavior and psychiatric disorders: findings from the Netherlands Mental Health Survey and Incidence Study (NEMESIS). Arch Gen Psychiatry 2001; 58: 85-91.

4 Collier KL, Bos H, Sandfort TGM. Homophobic name-calling among secondary school students and its implications for mental health. J Youth Adolesc 2013; 42: $363-75$.

5 Figueira I, Possidente E, Marques C, Hayes K. Sexual dysfunction: a neglected complication of panic disorder and social phobia. Arch Sex Behav 2001; 30: 369-77.

6 Segraves RT. Psychiatric illness and sexual function. Int J Impot Res 1998; 10 (suppl 2): S131-3.

7 Tiefer L. A new view of women's sexual problems: why new? Why now? J Sex Res 2001; 38: 89-96.

8 Carpenter D, Janssen E, Graham C, Vorst H, Wicherts J. Women's scores on the Sexual Inhibition/Sexual Excitation Scales (SIS/SES): gender similarities and differences. J Sex Res 2008; 45: 36-48.

9 Vanwesenbeeck I. Sexual violence and the MDGs. Int J Sex Health 2008; 20: 25-50. 
10 Castellanos-Torres E, Álvarez-Dardet C, Ruiz-Muñoz D, Pérez G. Social determinants of sexual satisfaction in Spain considered from the gender perspective. Ann Epidemiol 2013; 23: 150-6.

11 Bancroft J, Janssen E, Strong D, Carnes L, Vukadinovic Z, Long JS. The relation between mood and sexuality in heterosexual men. Arch Sex Behav 2003; 32: 217-30.

12 Chen $\mathrm{KC}$, Yeh TL, Lee $\mathrm{IH}$, Chen PS, Huang HC, Yang YK, et al. Age, gender, depression, and sexual dysfunction in Taiwan. Sex Med 2009; 6: 3056-62.

13 wylie K, Steward D, Seivewright N, Smith D, Walters S. Prevalence of sexual dysfunction in three psychiatric outpatient settings: a drug misuse service, an alcohol misuse service and a general adult psychiatry clinic. Sex Relation Ther 2002; 17: 149-60.

14 Bonierbale M, Lancon C, Tignol J. The ELIXER study: evaluation of sexual dysfunction in 4.557 depressed patients in France. Curr Med Res Opin 2003; 19: $114-24$.

15 Clayton AH, Montejo AL. Major depressive disorder, antidepressants and sexual dysfunction. J Clinic Psychiatry 2006; 67 (suppl 6): 33-7.

16 Hariri AG, Karadag F, Gurol D, Aksoy UM. Tezcan AE, Sexual problems in a sample of the Turkish psychiatric population. Compr Psychiatry 2009; 50: 353-60.

17 Bijl RV, Ravelli A. Current and residual functional disability associated with psychopathology: findings from the Netherlands Mental Health Survey and Incidence Study (NEMESIS). Psychol Med 2000; 30: 657-68.

18 Ormel J, Oldehinkel AJ, Nolen WA, Vollebergh W. Psychosocial disability before, during, and after a major depressive episode. A 3-wave populationbased study of state, scar, and trait effects. Arch Gen Psychiatry 2004; 61 387-92.

19 de Graaf R, ten Have M, van Dorsselaer S. The Netherlands Mental Health Survey and Incidence Study-2 (NEMESIS-2): design and methods. Int J Methods Psychiatr Res 2010; 19: 125-41.

20 American Psychiatric Association. Diagnostic and Statistical Manual of Mental Disorders (4th edn) (DSM-IV). APA, 1994.

21 Haro JM, Arbabzadeh-Bouchez S, Brugha TS, de Girolamo G, Guyer ME, Jin R, et al. Concordance of the Composite International Diagnostic Interview Version 3.0 (CIDI 3.0) with standardized clinical assessments in the WHO World Mental Health Surveys. Int J Methods Psychiatr Res 2006; 15: 167-80.

22 Kessler RC, Üstün TB. The World Mental Health (WMH) Survey initiative version of the World Health Organization ((WHO) Composite International Diagnostic Interview (CIDI). Int J Methods Psychiatr Res 2004; 13: 93-121.

23 Alonso J, Angermeyer M, Bernert S, Bruffaerts R, Brugha TS, Bryson $\mathrm{H}$, et al. Sampling and methods of the European Study of the Epidemiology of Mental Disorders (ESEMeD) project. Acta Psychiatr Scand 2004; 109 (suppl 420): 8-20.

24 de Graaf R, Ormel J, ten Have M, Burger H, Buist-Bouwman M. Mental disorders and service use in The Netherlands. Results from the European
Study of the Epidemiology of Mental Disorders (ESEMeD). In The WHO World Mental Health Surveys: Global Perspectives on the Epidemiology of Mental Disorders (eds RC Kessler, TB Üstün): 388-405. Cambridge University Press, 2008.

25 Andrews G, Peters L. The psychometric properties of the Composite International Diagnostic Interview. Soc Psychiatry Psychiatr Epidemiol 1998; 33: 80-8.

26 Wittchen HU. Reliability and validity studies of the WHO - Composite International Diagnostic Interview (CIDI): a critical review. J Psychiatr Res 1994; 28: 57-84.

27 de Graaf H, Meijer S, Poelman J, Vanwesenbeeck I. Seks onder je $25^{e}$. Seksuele Gezondheid van Jongeren in Nederland Anno 2005 (Sex under the Age of 25. Sexual Health of Young People in the Netherlands in 2005). Eburon, 2005

28 National Center for Health Statistics. Vital and Health Statistics. Evaluation of National Health Interview Survey Diagnostic Reporting. Series 2: Data Evaluation and Methods Research, No 120. US Department of Health and Human Services, 1994.

29 Skinner CJ, Holt D, Smith TMF. Analysis of Complex Surveys. Wiley, 1989.

30 Pascoal PM, de Santa Bárbara Narciso I, Pereirab NM. What is sexual satisfaction? Thematic analysis of lay people's definitions. J Sex Res 2014; 51; 22-30.

31 Bolle G, Griffioen T, Knegtering R. Seksuologie en psychiatrie (Sexology and psychiatry). In Seksuologie (Sexology) (eds L Gijs, W Gianotten, I Vanwesenbeeck, P Weijenborg): 513-33. Bohn Staffleu van Loghum, 2009.

32 de Graaf H. Seksueel gedrag en seksuele beleving in Nederland [Sexual behaviour and sexual experience in the Netherlands]. T Seksuol 2012; 36: 87-97.

33 de Graaf R, Bijl RV, Ravelli A, Smit F, Vollebergh WAM. Predictors of first incidence of DSM-III-R psychiatric disorders in the general population: findings from the Netherlands Mental Health Survey and Incidence Study. Acta Psychiatr Scand 2002; 106: 303-13.

34 George WH, Stoner SA. Understanding acute alcohol effects on sexual behavior. Ann Rev Sex Res 2000; 11: 92-124.

35 Daniell HW. Narcotic-induced hypogonadism during therapy for heroin addiction. J Addict Dis 2002; 21: 47-53.

36 Spring Jr WD, Willenbring ML, Maddux TL. Sexual dysfunction and psychological distress in methadone maintenance. Int J Addict 1992; 27 1325-34.

37 ten Have M, Nuyen J, Beekman A, de Graaf R. Common mental disorder severity and its association with treatment contact and treatment intensity for mental health problems. Psychol Med 2013; 43: 2203-13. 